GSA Data Repository Item 2019101 accompanies Lund, S.P., and Benson, L.V., 2018, A comparison of western Great Basin paleoclimate records for the last $3000 \mathrm{yr}$ : Evidence for multidecadal- to millennial-scale drought, in Starratt, S.W., and Rosen, M.R., eds., From Saline to Freshwater: The Diversity of Western Lakes in Space and Time: Geological Society of America Special Paper 536, p. 183-199, https://doi.org/10.1130/2019.2536(11).

\title{
Appendix 1: Supplementary Information
}

Paleomagnetic chronostratigraphy makes use of selected paleomagnetic secular variation (PSV) features (inclination highs/lows, declination east/west deviations) that can be identified in sediment sequences, correlated on a regional scale $(\sim 4000 \mathrm{~km})$, and dated by other means (radiocarbon or archeological context) in several independent records. Lund (1996) developed the first PSV chronostratigraphy for Holocene lake sediments in North America. Lund and Platzman (2016) and Lund et al. (2016) have updated that chronostratigraphy for the last 3000 years. Table DR1 lists the calibrated ages of inclination and declination features from western North America for the last 3000 years.

We have previously combined paleomagnetic and radiocarbon age estimates to build a composite chronostratigraphy for core PLC97-1 from Pyramid Lake (Benson et al., 2002). In this paper, we use only the PSV chronostratigraphy. The PSV-based and original composite-based (Benson et al., 2002) time/depth variations within core PLC97-1 are shown in Figure DR1. There is usually less than a 30 -year difference between the two chronologies, but it does get as large as a $\sim 100$ year difference around $1500 \mathrm{AD}$.

We have carried out paleomagnetic studies on core WLC001 from Walker Lake. The core was cut into $\sim 30 \mathrm{~cm}$ intervals so we were able to reconstruct the inclination record but not the declination record. The inclination variability and identifiable PSV inclination features for core WL001 are shown in Figure DR2. We tied the PSV ages from WLC001 into core WLC002 using proxy correlations. The final PSV-based age/depth plot for core WLC002 is shown in Figure DR3. The original radiocarbon-based age/depth curve for WLC002 is also shown in Figure DR3. The two records are almost identical from AD 1000 to the present. But, the PSV chronostratigraphy is almost 200 years different from the radiocarbon chronology about $300 \mathrm{BC}$.

\section{References Cited}

Benson, L., Kashgarian, M., Rye, R., Lund, S., Paillet, F., Smoot, J., Kester, C., Mensing, S., Meko, D., and Lunstrom, S., 2002, Holocene multidecadal and multicentennial droughts affecting northern California and Nevada: Quaternary Science Reviews, v. 21, p. 659-682, https://doi.org/10.1016/S0277-3791(01)00048-8.

Lund, S., 1996, A comparison of Holocene paleomagnetic secular variation records from North America: Journal of Geophysical Research, v. 101, p. 8007-8024, https://doi.org/10.1029/95JB00039. 
Lund, S., and Platzman, E., 2016, Paleomagnetic chronostratigraphy of late Holocene Zaca Lake, California: The Holocene, v. 26, no. 5, p. 814-821, https://doi.org/10.1177/0959683615618255.

Lund, S., Goman, M., and Joyce, A., 2016, Paleomagnetic chronostratigraphy of Holocene Laguna Minucua, Oaxaca, Mexico: Quaternary International, v. 469, pt. B, p. 1-10. 
Table DR1: Ages and depths of PSV features

\begin{tabular}{lc}
\hline $\begin{array}{l}\text { PSV } \\
\text { Feature }\end{array}$ & $\begin{array}{c}\text { True Age } \\
(\text { AD/BC) }\end{array}$ \\
\hline D $\alpha$ & $1900 \pm 50$ \\
I $\alpha$ & $1754 \pm 35$ \\
D $\beta$ & $1612 \pm 84$ \\
I & $1578 \pm 50$ \\
D $\delta$ & $1350 \pm 100$ \\
I $\beta$ & $1336 \pm 60$ \\
I & $1223 \pm 63$ \\
D1 & $1058 \pm 80$ \\
I1 & $1039 \pm 68$ \\
D2 & $820 \pm 88$ \\
I2 & $747 \pm 102$ \\
D3 & $612 \pm 68$ \\
I3 & $432 \pm 61$ \\
D4 & $400 \pm 76$ \\
I4 & $161 \pm 65$ \\
D5 & $43 \pm 117$ \\
I5 & $-203 \pm 69$ \\
D6 & $-475 \pm 97$ \\
I6 & $-675 \pm 66$ \\
D* & $-900 \pm 75$ \\
I* & $-1050 \pm 75$ \\
D** & $-1100 \pm 75$ \\
\hline
\end{tabular}




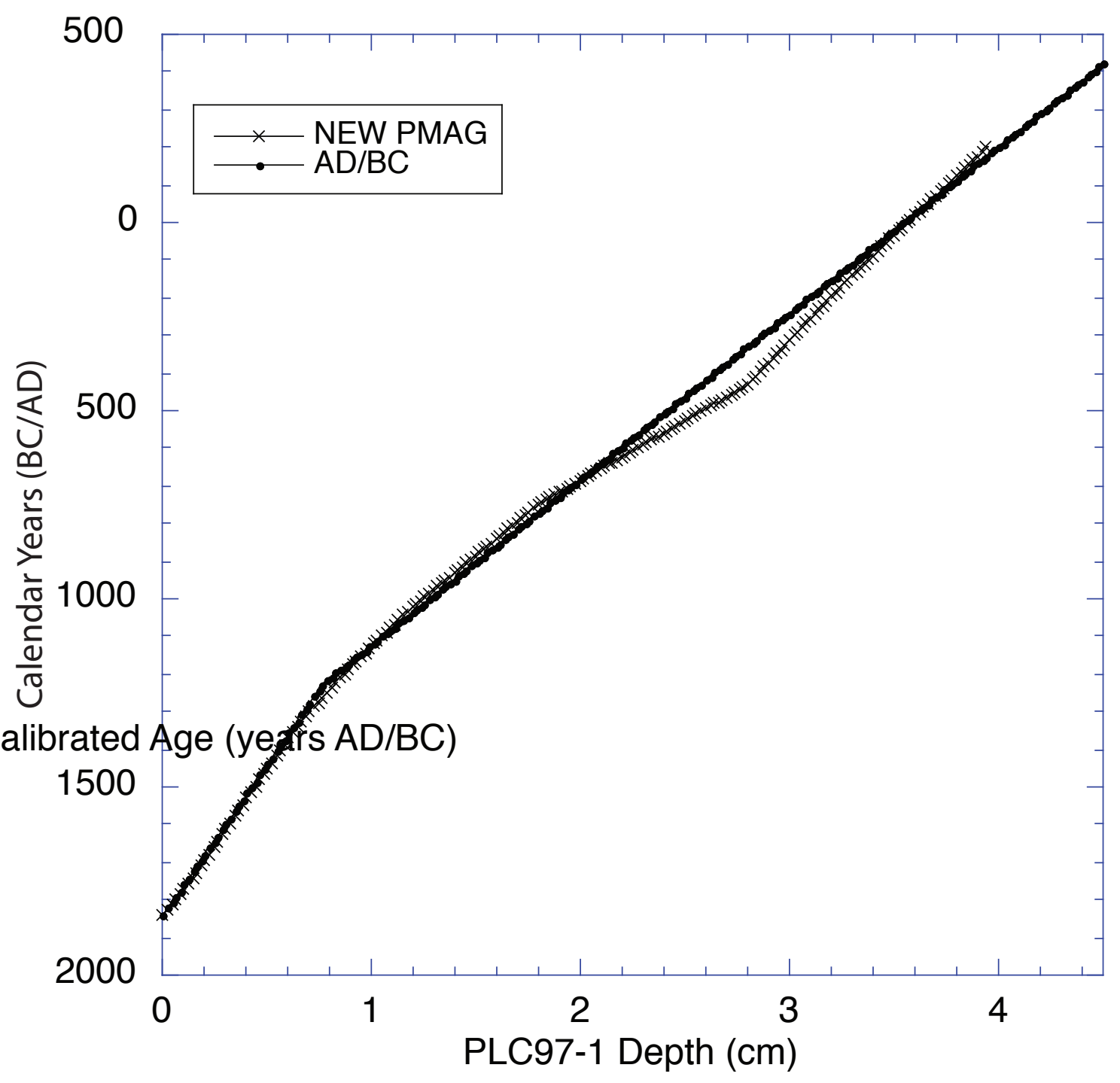

Figure DR1

Time/depth plot for core PLC97-1 (Pyramid Lake) showing the original chronology for the core (AD/BC) and our revised paleomagnetic chronology (NEW PAG) used in this paper. 


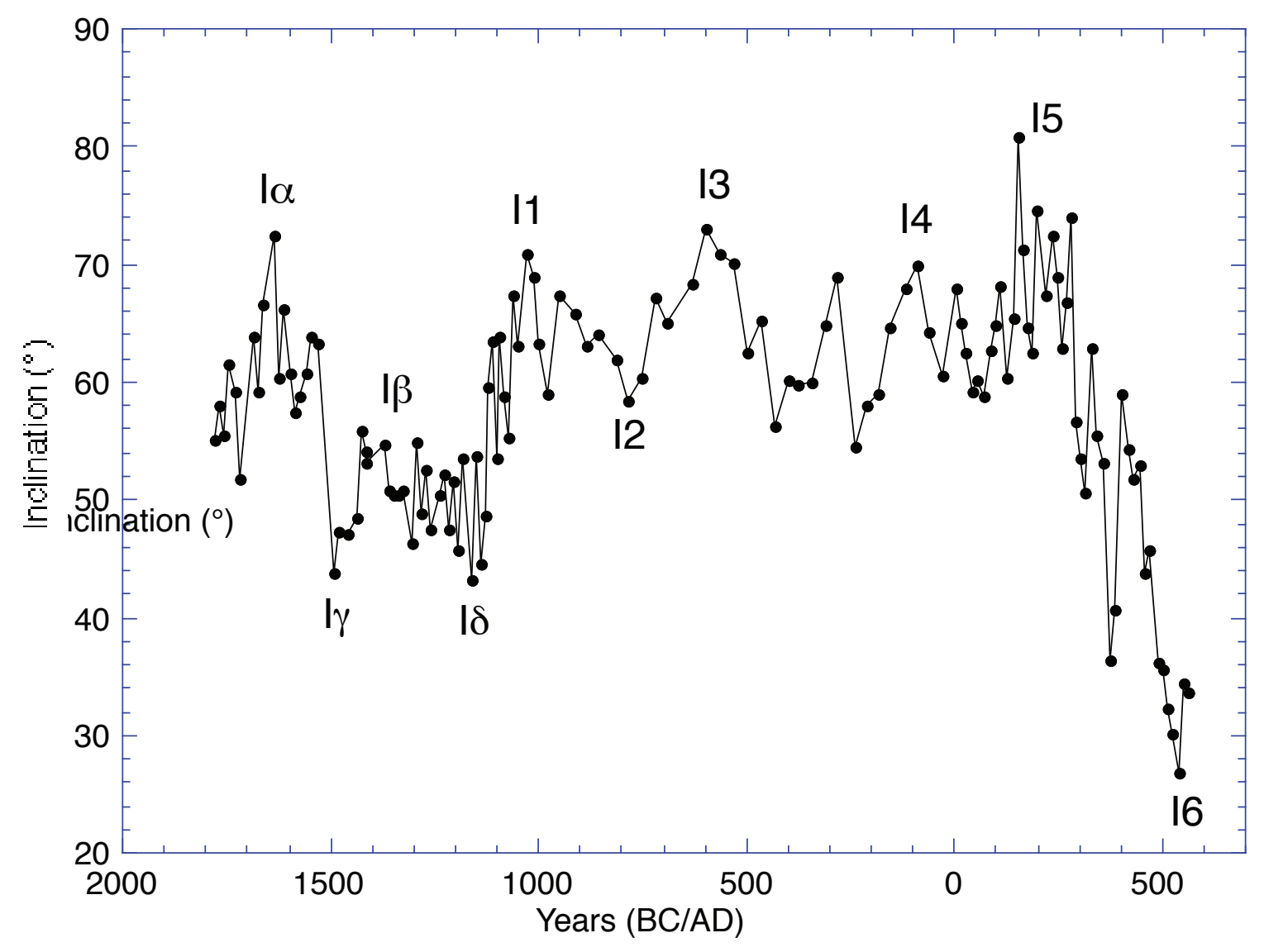

Figure DR2

Paleomagnetic inclination record for Walker Lake core WLC001. Selected paleomagnetic secular variation (PSV) features are shown. See text for further discussion. 


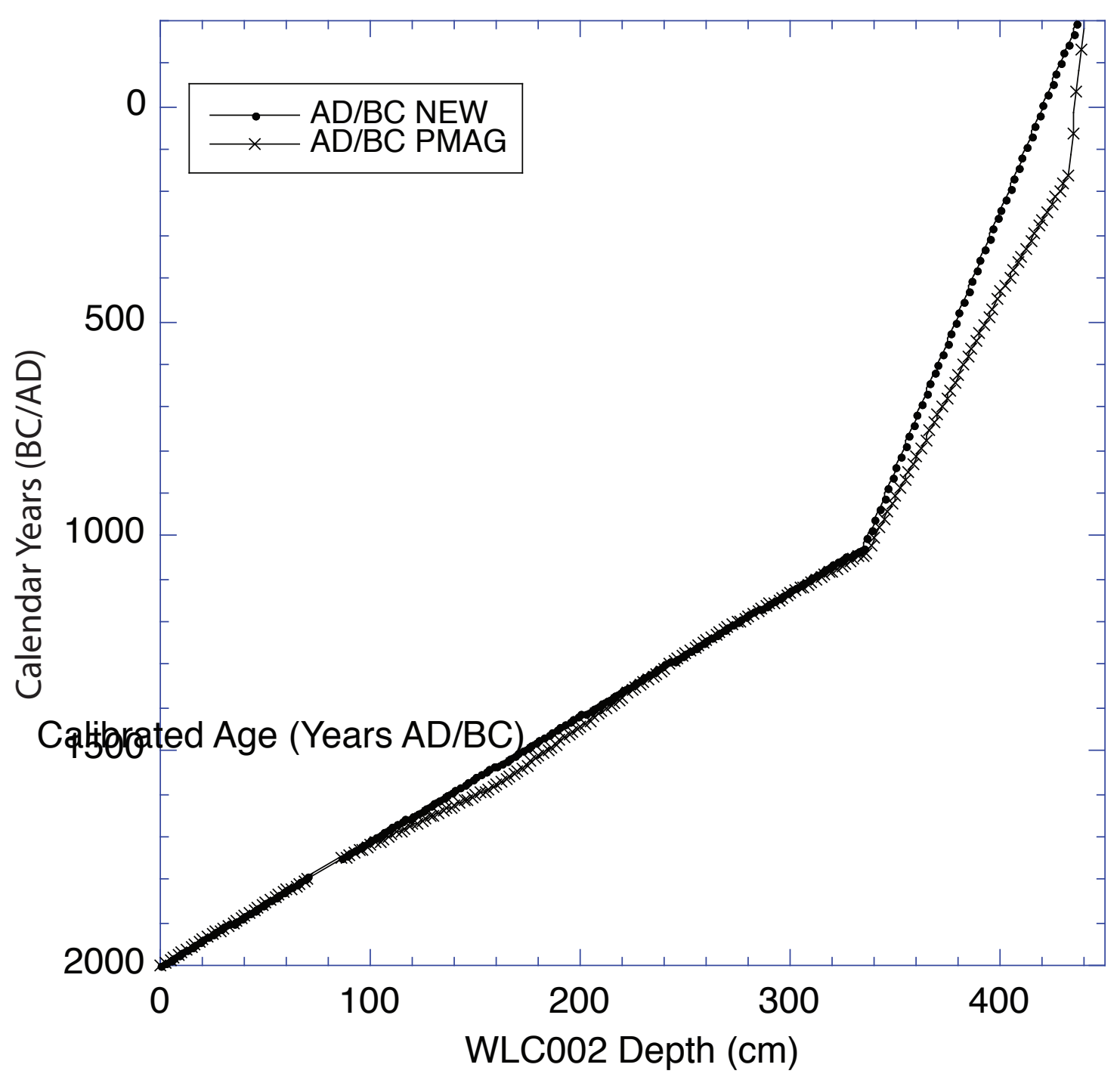

Figure DR3

Time/depth plot for core WLC002 (Walker Lake) showing the original chronology for the core (AD/BC NEW) and our revised paleomagnetic chronology (AD/BC PMAG). 